\title{
Promoting interdisciplinary education - the Vienna Doctoral Programme on Water Resource Systems
}

\author{
G. Blöschl, G. Carr, C. Bucher, A. H. Farnleitner, H. Rechberger, W. Wagner, and M. Zessner \\ Centre for Water Resource Systems, Vienna University of Technology, Karlsplatz 13/222, 1040, Vienna, Austria
}

Correspondence to: G. Blöschl (office@waterresources.at)

Received: 24 October 2011 - Published in Hydrol. Earth Syst. Sci. Discuss.: 9 November 2011

Revised: 30 January 2012 - Accepted: 3 February 2012 - Published: 13 February 2012

\begin{abstract}
The Vienna Doctoral Programme on Water Resource Systems (DK-WRS) is a programme that aims to educate students in interdisciplinary water science through cutting edge research at an international level. It is funded by the Austrian Science Fund and designed to run over a period of $12 \mathrm{yr}$ during which 80 doctoral students are anticipated to graduate. This paper reports on our experiences of setting up and implementing the Programme. We identify three challenges: integrating the disciplines, maintaining depth in an interdisciplinary programme, and teaching subjects remote to each student's core expertise. To address these challenges we adopt a number of approaches. We use three levels of instruments to foster integration across the disciplines: joint groups (e.g. a joint study programme), joint science questions (e.g. developed in annual symposia), and joint study sites. To maintain depth we apply a system of quality control including regular feedback sessions, theses by journal publications and international study exchange. For simultaneously teaching students from civil and environmental engineering, biology, geology, chemistry, mathematics we use visually explicit teaching, learning by doing, extra mentoring and by cross relating associated subjects. Our initial assessment of the Programme shows some very positive outcomes. Joint science questions formed between students from various disciplines indicate integration is being achieved. The number of successful publications in top journals suggests that depth is maintained. Positive feedback from the students on the variety and clarity of the courses indicates the teaching strategy is working well. Our experiences have shown that implementing and running an interdisciplinary doctoral programme has its challenges and is demanding in terms of time and human resources but seeing interactions progress and watching people grow and develop their way of thinking in an interdisciplinary environment is a valuable reward.
\end{abstract}

\section{Introduction}

Most real problems in water resources science and engineering are interdisciplinary. For example, a shallow aquifer providing drinking water requires sustainable management. Management must consider the interactions between the aquifer and overlying surface water. This requires an understanding of the hydrology, chemistry and biology of streamaquifer interactions along with the political economy driving extraction, pollution and other water uses. Managing floods requires an understanding, not only of hydrology but also of factors governing runoff, such as meteorology and plant physiology. Tools such as remote sensing provide valuable information. Engineering solutions involve mechanics, optimisation, systems engineering and economics. Hard solutions can increasingly provide only one part of the management strategy, and an understanding of economics, governance and societal participation in decision-making helps determine appropriate management.

From a research perspective, the most interesting science questions are also interdisciplinary. To understand aquifers, questions surround the interplay of chemical, physical and biological processes. How can we measure aquifer processes in the field and laboratory? How can we upscale laboratory findings to the field scale, in the presences of multi-scale heterogeneity and preferential flow? How can we build models that replicate processes that can be evaluated at the field scale? For understanding flood processes, interesting science questions are: What are the mechanisms of runoff generation at multiple scales? How can we capture flood processes by remote sensing and other measurement techniques? How can the risks posed by floods be quantified in coupled human/natural systems?

People with the capacity to work in an interdisciplinary manner are needed to address society's interdisciplinary problems (Wolman, 1977). Doctoral level education is important because this is the stage where students are trained to 
be researchers and are prepared for their future careers. Interdisciplinary research training is of critical importance for arming the future generation with the skills to address society's global challenges.

Interdisciplinary is about synthesis of fragmented knowledge and understanding collected by a variety of disciplines (Blöschl, 2006). It involves, "bringing together people and ideas from different disciplines to jointly frame a problem, agree on a methodological approach and analyze the data" (Golde and Gallagher, 1999, p. 281). Several interdisciplinary doctoral programmes have been set up with similar objectives. They generally follow one of three approaches:

a. The doctoral programme is attached to a multidisciplinary research centre. Programmes run out of multi-disciplinary departments such as computer science, hydrology or development studies characterise this approach.

b. Students enrolled in the doctoral programme remain attached to their distinct disciplinary departments but are brought together through a central programme. The Bio-X programme at Stanford University brings together PhD students from scientific and engineering disciplines focussed around biosciences research through grants to support their interdisciplinary training (Nelson, 2011).

c. Short-term (perhaps annually repeated) programmes bring together a collection of research students, who work intensively together, for example during a graduate summer school. The University of Illinois Hydrologic Synthesis Project follows this model, bringing together a small group of hydrology research students from a variety of disciplinary backgrounds for six week residential summer institutes to address science problems (Thompson et al., 2011).

There are benefits and challenges to each of the approaches. Multi-disciplinary research centres and their associated doctoral programmes demonstrate interdisciplinary success by their very existence (Golde and Gallagher, 1999). Such programmes tend to be applied in areas where merging of disciplines into new fields has become widely accepted, but they are rarely found where research at disciplinary interfaces is just beginning to be explored. The creation of a central programme or centre to which students are affiliated allows students to develop and maintain a strong relationship to their own research field, along with access to appropriate human and physical resources that help them achieve their $\mathrm{PhD}$. For academic career development, a strong disciplinary background is considered to be essential (Nelson, 2011). Short-term programmes are thought to offer the benefits of a long-duration programme (development of new skills, exposure to external experts and expansion of understanding and awareness) over a relatively short period of time. However, their challenges include harnessing human and financial resources (Thompson et al., 2011).

The question remains as to which approach is most effective, or perhaps more importantly, which features of the approaches used in an interdisciplinary doctoral programme are most effective. In this paper we describe our experiences of setting up and implementing a multi-disciplinary doctoral programme in water resource systems. Our aim is to arm others thinking about or planning a similar endeavour with some guidance as to what works well, what is particularly challenging, and which areas need careful attention, based on our own experiences.

\section{Aims and strategy of the Vienna Doctoral Programme on Water Resource Systems}

\subsection{Aims of the programme}

Interdisciplinary, international and cutting edge research: The Programme was initiated to produce top graduates capable of conducting advanced, independent research which cuts across multiple disciplines. Each Doctoral Programme graduate should be an in depth researcher in their chosen research field who has made an original contribution to science and should also be able to understand and communicate with specialists in other disciplines. They should have developed critical reasoning skills necessary to discover new theories and incorporate new experimental evidence. They should be able to approach water resource problems from various viewpoints in an integrated way. Hence, they should not only know their subject in great detail, but also be able to place their research topic in the broader context of understanding and managing water resource systems in an innovative, sustainable manner. Graduates learn that they must compete with, and collaborate with world leaders in their field of specialisation. The Programme is international, and emphasises to graduates that there is one international research community.

An essential element of interdisciplinary research is to understand how different disciplines think (Castán Broto et al., 2009; Petrie, 1976). There is great diversity in ways of thinking and mindsets among the multitude of disciplines linked to the water sciences. When the disciplines span only the natural sciences there are great differences in world views, such as those of physicists and ecologists (Table 1). When the disciplines span both the natural and social sciences there can be even greater disparity in views and approaches. Positivist natural scientists search for one truth, while pluralist social scientists accept that there are many different world views which tend to be dependent on who or what is constructing the issue (Price, 2003; Redclift, 1998). An essential element of interdisciplinary training is to teach students how other disciplines think. 


\subsection{Strategy of the programme}

The success of the Programme hinges on whether interdisciplinarity is achieved, whether cutting edge research is conducted and whether the education system forms graduates that can operate in, and benefit from, an interdisciplinary environment. The strategy chosen to implement the Programme is therefore extremely important. It was noted back in the 1960s that designing an education programme for water resources (an area of specialisation) presents many problems when compared to designing a programme for a specific discipline (Hufschmidt, 1967). Three challenges were identified here that were anticipated to be potential barriers to implementing an interdisciplinary programme: (1) integrating the disciplines, (2) maintaining depth in an interdisciplinary programme, and (3) teaching subjects remote to each students' core expertise. In this section we explain these challenges and in Sect. 3 we describe our approaches for overcoming them.

\subsubsection{Challenge \#1: integrating the disciplines}

Universities are separated into discrete disciplines. Strong cultural identity is associated with many disciplines, and university administration and funding structures affirm disciplinary boundaries (Wagner et al., 2011). Interdisciplinary centres are a relatively new structure, and their acceptance into traditional systems is essential. In some situations, integration between disciplines may evolve as research agendas or students demand courses which bring multiple disciplines together, such as the environmental sciences (Wolman, 1977). The ambitions of senior researchers to explore areas at the boundaries of traditional disciplines can also drive linkages. However, at the doctoral level integration is likely to need support due to the short timescale of the doctorate (three to four years) and the level at which candidates work (conducting research rather than driving a research agenda). Special efforts to achieve integration were therefore prioritised.

Three levels of integration were identified (Fig. 1). The first level of integration focuses around joint groups and includes approaches that aim to simply mix students together and give them an initial experience of other world views. Second level integration is more intensive, and focuses on developing joint science questions and enhancing the individuals' capacity to understand and synthesise alternative systems and methods into their own work. The third level of integration aims to foster active interdisciplinary exchange through joint research with study sites as a focus. More details of the activities conducted at each level are given in Sect. 3.2.

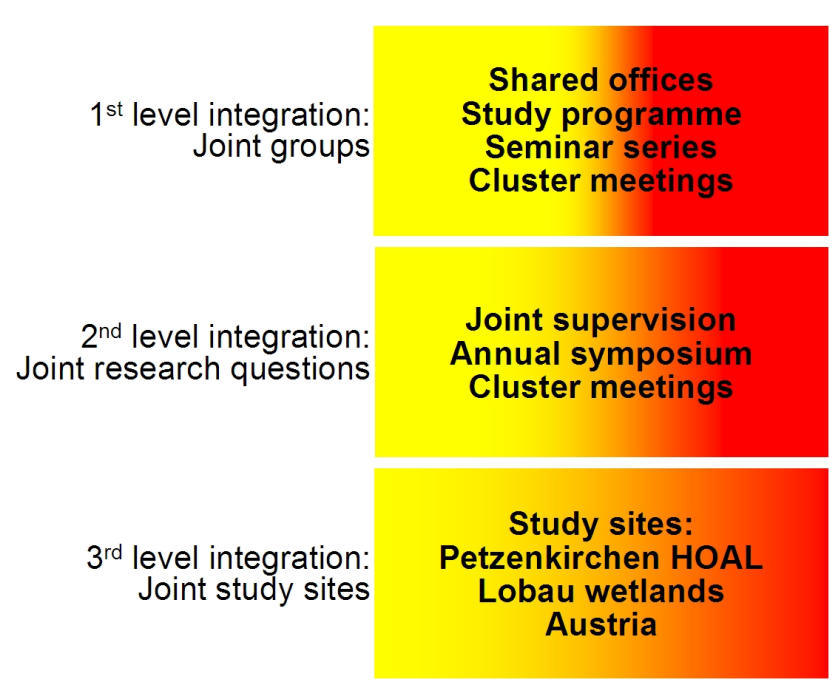

Fig. 1. Three levels of integration in the Vienna Doctoral Programme on Water Resource Systems.

\subsubsection{Challenge \#2: maintaining depth in an interdisciplinary programme}

Deep understanding of a specific topic is essential in order that a graduate makes a novel contribution to knowledge, a primary requirement of a $\mathrm{PhD}$. The nature of some interdisciplinary research, for example whereby one researcher includes ideas, methods and approaches from many disciplines, can lead to broad knowledge and understanding of many topics, but on a more superficial level. The potential danger faced by interdisciplinary research students is that they spread themselves over many different areas and have insufficient time to fully develop their skills in a particular research area.

Students in the Doctoral Programme must achieve deep expertise in their area of specialisation. However, they must also be able to link their expertise to the expertise of other specialists. The Programme developed and applied an Apple Core concept of education where the breadth of the apple core indicates breadth of expertise (Fig. 2). PhD studies should be narrow, deep and focussed, but an interdisciplinary education should raise awareness to, and capacity to relate to other narrow and focussed research areas. A system of quality control was developed to ensure that the Programme sought to create specialists rather than generalists. This included a rigorous candidate selection process, regular presentation of material to internal and external specialist audiences, production of a thesis proposal and its satisfactory defence, a thesis comprised of peer reviewed journal papers and a thesis examination by international experts (in line with EU standards). 
Table 1. Different world views of physicists and ecologists (mind sets) (from Harte, 2002).

\begin{tabular}{ll}
\hline Physics & Ecology \\
\hline The more you look, the simpler it gets & The more you look, the more complex it gets \\
Primacy of initial conditions & Primacy of contingency and complex historical factors \\
Universal patterns; search for laws & Weak trends; reluctance to seek laws \\
Predictive (chaos notwithstanding) & Mostly descriptive, explanatory \\
Central role for the ideal systems & Disdain for caricatures of nature \\
\hline
\end{tabular}

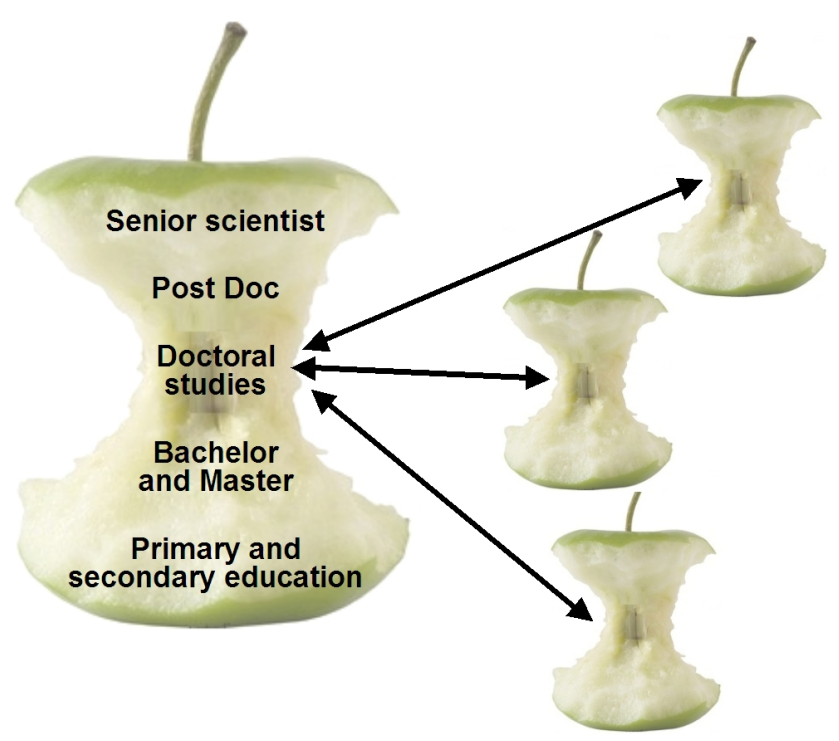

Fig. 2. Apple core concept of education: the width of the apple shows the breadth of topics covered at each stage of education. Doctoral studies are narrow, focussed and deep. A significant feature of the Doctoral Programme is that all candidates are constantly exposed to the specialist work of other candidates (illustrated by the other apples with arrows showing interaction) thereby raising their capacity to relate to other areas of specialisation.

\subsubsection{Challenge \#3: teaching subjects remote from students' core expertise}

Doctoral Programme students have a diverse range of academic backgrounds. Communication is one of the major challenges for teachers facing a class of heterogeneous students. The teacher must communicate the information on their topic to a group with very different understandings of the concepts and information being presented. During the first and second year of the Programme students are expected to attend an array of courses from outside their own area of specialisation. A significant challenge to teaching staff is effectively conveying their material to students with little or no background in the subject being taught. For example, how can calculus be taught to biologists? How can soil science be taught to structural engineers?

\section{Implementation and assessment}

\subsection{Set up of the programme}

In 2009 the Centre for Water Resource Systems was set up as the home for the Doctoral Programme. The interdisciplinary Centre is attached to the vice-rectorate of research, which demonstrates its importance to Vienna University of Technology. The university was instrumental in setting up the Centre and providing strategic office resources to support the interdisciplinary initiative. Funding was secured from the Austrian Science Fund and this backing, specifically for interdisciplinary programmes, is an essential element for the set up and implementation of the Programme. Matching funds were provided by the Vienna University of Technology. Currently, 23 students, six academic staff (the faculty) and one full-time coordinator are engaged in the Programme. Six students are fully supported by the Austrian Science Fund, two students are supported by Vienna University of Technology, one is supported by the Schlumberger Foundation. These students are able to designate 100 per cent of their time to their personal research and education and are expected to complete their PhD in four years. The remaining students are supported through other project related funds attached to the Faculty. They also take part in university project work, are involved in teaching and some have research related administration responsibilities. These students are given a longer time frame to complete their PhDs (4-5 yr). The Austrian Science Fund supports programme activities, conference attendance, education training etc. for all students. It is planned that the Programme will run until 2022 and will engage a total of 80 students.

A recruitment campaign for the first intake of students took place in mid 2009. Advertisements for nine fully funded positions (8 studentships and one post-doctoral research and co-ordination position) were announced in more than 20 international science newspapers or careers websites. The Programme received more than 600 applications from 74 countries which shows interest across the world in both water resources research and in interdisciplinary doctoral programmes. We imagine that the breadth of the advertising campaign helped achieve the high number of applications. From the 600 applications, the faculty put together a shortlist 
of 25 candidates who were invited to Vienna to take part in a rigorous selection seminar. The seminar aimed to not only identify the most academically promising candidates but to also distinguish individuals who showed strong teamworking capabilities and motivation to be part of an interdisciplinary programme. The decision to base acceptance on social skills and team-working as well as academic merit was made because it was felt that these characteristics would be essential for overcoming some of the challenges of integrating the disciplines.

The selected candidates are all highly motivated and enthusiastic about water sciences and interdisciplinary research. They have strong interpersonal and communication skills and show a commitment to personal and professional development. They also represent a range of nationalities (students in the Programme come from Canada, USA, Germany, Netherlands, Spain, Czech Republic, Poland, Slovakia, Hungary, Austria, Italy and Ethiopia) and have a desire to work in international and multi-cultural environments. They are all highly proficient in English (the working language of the Programme).

\subsection{Integrating the disciplines (Challenge \#1)}

Three levels of instruments are used to achieve integration between the students and their research fields (Fig. 1). First level instruments are about forming joint groups where ideas and experiences can be exchanged. They include shared offices, courses, seminar series and cluster meetings. Second level instruments are used to develop joint research questions and include joint supervision and symposia. Third level instruments create an environment for joint learning by doing and are focussed around shared study sites.

\subsubsection{First level integration - joint groups}

Joint group activities are designed to create a situation where students exchange ideas and experiences. The intention is to mix students from different disciplines together to give them the opportunity to learn about each other's scientific world views (mind sets) and to perhaps question their own positions and views.

Shared offices - students are jointly affiliated to both their supervisors' research institute and to the Centre for Water Resource Systems. Office space is provided within the Centre for a multi-disciplinary mixture of students which ensures day-to-day mixing of different disciplinary views. This strategy generally works well and the eclectic mix leads to many interesting discussions over coffee on topics as specific as thesis and academic paper structure, and as general as meeting the millennium development goals ambition of halving the number of people without access to water and sanitation by 2015 (http://www.un.org/millenniumgoals/environ).

Students' affiliation to the supervisors department was more weakly cemented in some cases, particularly for individuals new to their supervisors' research field and to the University. During the first year of the Programme some students wanted to be more greatly integrated into their supervisors' institutes. Supervisors responded to this by setting up meetings where the new students could introduce themselves and their work and by ensuring their student received invitations to departmental seminars and discussion sessions. These actions helped, but the kind of informal integration which the students were expecting where they could happily knock on the doors of their disciplinary colleagues with questions and problems naturally took longer to develop. The annual symposium which took place at the end of the first year and gathered together all students seemed to strengthen bonds between individuals linked to specific departments. This experience suggests that linking multi-disciplinary students through shared office space is very effective but research students also wish to have a strong sense of disciplinary identity. This should also be supported through integration by the supervisor into their department.

Study programme - all students took a compulsory basic study programme in the first year of the Programme (Table 2) Lecturers noticed that courses led to some very interesting experiences that showed the different disciplines world views. For example, the lecturer on modelling and simulation methods highlighted the types of differential equations used in different areas of water resource systems. At the beginning of the course most of the students were familiar only with the differential equations from their own field. It took a while for them to understand that there are identical differential equations for different chemical, biological and physical systems. For instance, the diffusion equation plays to both subsurface water flow and heat conduction. When they realised the similarities they also realised that the same solutions and modelling methods can be used across disciplines for specific applications. This was made possible by interactive discussions during courses when the students explored their views and experiences of differential equations in their field and learned, not just from the lectures, but also from each other (group learning).

Students have the opportunity to select several advanced courses from a range offered by the Programme and the University (Table 2). These detailed courses develop students' understanding of the issues and methods used in different research fields. They also lead to further interaction between students through joint practical and research assignments. For example, the advanced course on spatial data from photogrammetry and remote sensing brought together hydrology, remote sensing and water quality research students to collaborate on a practical assignment. Students found that remote sensing and hydrology were strong collaboration areas because of the interplay between remote sensing methods that detect soil moisture and hydrological processes at the land surface. Remote sensing can provide hydrologists with valuable data and information on moisture conditions while hydrologists can help remote sensing researchers to interpret 
Table 2. Courses of the compulsory basic study programme and selective advanced programme.

\begin{tabular}{l}
\hline Basic study programme (compulsory) \\
\hline Basics of stochastic mechanics \\
Health related water quality targets and urban water management \\
Modelling and simulation methods in water resource systems \\
Resource and river basin management \\
Spatial data from photogrammetry and remote sensing \\
Water resource systems and socio-economic concepts \\
\hline Advanced study programme (selective) \\
\hline Case studies of integrated water resources analyses \\
Isotope hydrology \\
Methods in aquatic molecular ecology and microbial diagnostics \\
Psychology of sustainability \\
Resource management design \\
Spatial data from photogrammetry and remote sensing (practical) \\
Structural optimisation
\end{tabular}

their data through providing information and understanding of the processes taking place at the surface.

Intensive, block courses delivered by internationally renowned lecturers were offered to all students of the Programme. Topics include economics and governance of water, and modelling the fate and transport of microbes in aquatic systems. These courses brought together a diverse collection of students enrolled in the Programme, together with external students and practitioners from the region. The discussion sessions in these courses were particularly useful for showing how different disciplines recognise broad water resource challenges. For example, microbiologists tended to contextualise water resource challenges in terms of providing safe drinking water and sanitation, while hydrologists tended to contextualise them in terms of hard and soft engineering solutions, and associated modelling challenges.

All study programmes were generally well received and all students passed all necessary courses. During a feedback session on course quality, students noted that they learnt more from courses with a good introduction and which were highly interactive with plenty of opportunity to ask questions. Time management and stimulating motivation were sometimes challenges. Students were highly motivated to work on their research and students sometimes felt that courses detracted time away from research. The faculty encouraged students to think broadly about their education and emphasised that individual research can benefit, and each student's capacity as a water resource professional can be enhanced by devoting time and energy to subjects unconnected to their current research area. Two years into the Programme students are realising that they gained a lot by attending general courses which covered background material on health related water quality targets and urban water management, and resource and river basin management, and economics and governance of water. Several students have noted how their understanding of the complexities of agricultural pollution, regulation and economics has brought in new dimensions to their own research.

Seminar series - invited speakers from around the world have given seminars on many different aspects of water resource systems - water disinfection and microbial water quality, vegetations impact on evapotranspiration, nutrient balance in rivers, life-cycle optimisation for maintenance and monitoring of bridges and ships - to name just a few. These seminars were all specifically designed for an interdisciplinary audience and speakers presented their material in an exceptionally clear and accessible manner. The seminar series aims to create an environment where students learn about cutting edge approaches and paradigms used in other disciplines, exchange ideas and think creatively about potential applications to their own area of specialisation.

Cluster meetings - to open-up disciplinary borders, all members of the Programme are allocated to at least one research cluster group (Fig. 3). Cluster groups are formed around the themes of risk, health related water quality, modelling and systems analysis, water resource management and soil moisture and scaling, and one of the study sites covered by the Programme (the Petzenkirchen Hydrological Open Air Laboratory - HOAL). Many people are members of more than one cluster group and the overlap aims to further integrate the groups. The groups hold regular meetings where they either discuss a journal paper (journal clubs), have unstructured discussions or brainstorming sessions, or discuss each other's work. The aim of the cluster groups is to create a forum where people with different disciplinary backgrounds meet around a central theme which focuses their attention. For some individuals the cluster meetings are an essential forum for making decisions on the direction of their research. For example, the HOAL group meet regularly to discuss which instruments would be needed and feasibly installed into the research catchment. Each member of the group has an important stake in these decisions which affects which data are available for their thesis. For other groups the cluster meetings are less essential for completion of their doctorate but instead provide a place where they can think about the value of their work for society, or identify ideas for future work.

About one year into the Programme, the modelling and systems identification cluster wanted to inject some creativity into their meetings. They noted that their meetings tended to consist of a presentation by one member of the group outlining their method and application, some discussion between similar discipline members while other discipline members looked on, sometimes bored. The group decided to change their strategy to try to find a more integrated approach to cluster meetings. They wanted to be more problem focussed and think creatively on how they could apply their methods to alternative settings. They chose to hold a brainstorming session to explore the question "which research topics can be 


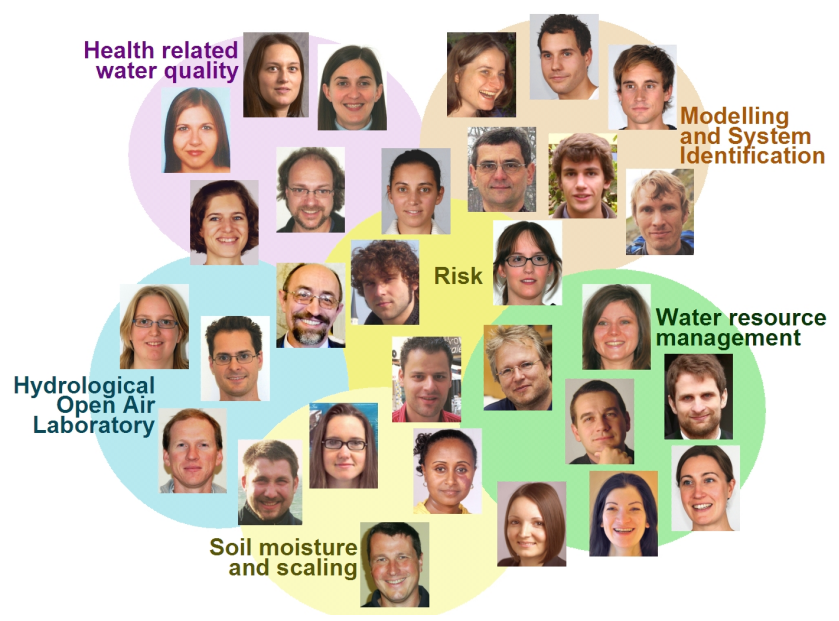

Fig. 3. Research cluster groups of the Vienna Doctoral Programme on Water Resource Systems.

chosen to easily generate interdisciplinary scientific output - open problems versus state-of-the-art methods?". This led to the identification of many different research problems (for example, the need for a large number of hydrological input parameters) and possible methods (for example, model order reduction). The creative ideas that emerged from this workshop fuelled a joint question on how model reduction techniques developed for structural mechanics could be applied to rainfall/runoff modelling. These experiences of cluster groups show that they are very important forums for exchange, learning and creativity between multi-disciplinary researchers.

\subsubsection{Second level integration - joint research questions}

Joint research questions are at the heart of the interdisciplinary collaboration as this is where most of the intellectual exchange between doctoral students occurs. In line with the Apple Core concept (Fig. 2), PhD studies should be narrow, deep and focussed but, to enable interdisciplinarity, two or more students should jointly contribute to a wider science question and interact in the process. For example, one of our overarching research questions is "what are the processes controlling phosphorus dynamics in a small agricultural catchment?". There are a number of physical, chemical and biological processes relevant to this question, each of which are dealt with by a student who is an expert in their own speciality but is able to understand the language and the mindset of the students from the other disciplines.

For example, since phosphorus is mainly transported attached to sediment particles we need to know where and why erosion occurs in the catchment to understand phosphorus transport on the land surface. We also need to know the processes controlling the dissolution, precipitation, sorption and desorption processes of phosphorus. These are two interesting research questions per se and they contribute to the overarching research question. Also, direct interactions between individual students are needed for them to achieve their own specific research goals. For instance, erosion is driven by surface runoff controlled by topography and roughness, and conversely, erosion affects the microtopography. The remote sensing student therefore needs the expertise of the hydrology student (or supervisor) in terms of what are hydrologically meaningful surface features, and the hydrological student needs the expertise of the remote sensing student (or supervisor) in terms of the interpretation of the roughness and topographic results of the Lidar analysis. Similarly, a soil science question addresses where preferential flow paths occur, and this is connected to the spatial soil moisture distribution within the catchment.

The individual questions contributing to the phosphorus dynamics example are illustrated in Fig. 4. Typically, each individual science question will result in a journal paper. The student with the core expertise will be the first author, a student (or supervisor) involved from a different discipline will be second or third author. To enable the interactions between students from different disciplines and encourage joint questions the doctoral programme adopted three main instruments: joint supervision, annual symposium and cluster groups.

Joint supervision - each student has a main supervisor and a secondary supervisor, each based in a different university department. The Programme exploited existing cooperations between faculty members selected to be part of the Programme. Prior collaborations had taken place between all members of the faculty and they were therefore familiar and comfortable working with each other. Regular meetings, particularly during the initial stages of the $\mathrm{PhD}$, took place between the set of supervisors and the student, with the specific intention of searching out and developing research questions which span the disciplines. This approach is stimulating for the supervisors and provides the student with the opportunity to learn about research question development. For example, a joint research question on the potential use of biological and artificial tracers for examining and predicting the transfer of dangerous microbes to groundwater and their potential for groundwater contamination was developed by microbiologists and hydrologists. They are interested in how the interactions between virus particles, colloids and aquifer matrices affect the movement of pathogenic viruses through groundwater. This work will ultimately help inform our understanding of the risks to drinking water aquifers, and provide information on which management strategies (such as the proper delineation of protection zones) can be based.

Annual symposium - this aims to provide a forum for integration between all members of the Doctoral Programme and for providing a creative, informal environment for exploring potential joint research questions (Fig. 5). During the first annual symposium extended poster discussion 


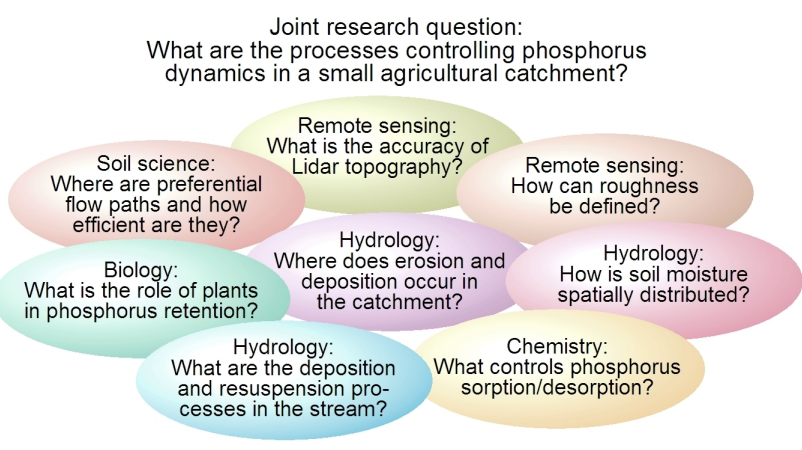

Fig. 4. Example of an overarching joint research question showing the interplay between the disciplines in addressing the question. The individual questions contributing to the joint research question are typically addressed in one research paper.

sessions were held where each member of the Programme presented a poster. These sessions provided a forum for discussion of each other's work, supported creative development of joint research questions and explored novel approaches for addressing existing research problems. Many examples of creative thinking emerged during the symposium. A joint research question was put together on how flow paths of agricultural fertilisers (nitrogen and phosphorus) in the Petzenkirchen HOAL study catchment are influenced by weather events. This emerged though discussion between water quality, hydrology and soil science researchers who all brought their own skills and expertise to the discussion. A water quality researcher and a remote sensing researcher discussed how spatial analysis techniques could be applied to measure the extent of foam cover on surface water. This work would address a critical need in water quality monitoring and is being developed further by the researchers within the Programme.

During the annual symposium students and faculty discovered that, as expected, one of the major difficulties was with communication. Acronyms were forbidden and technical terminology was meant to be kept to minimum. This is no easy feat and all were encouraged to ask when something was not clear. For example, a mechanics student who was running an experiment on structural stability by placing masonry on a shaking platform described how the method required to, "increase the excitation level until the load carrying capacity is exceeded". This was clarified to show that it meant, "shake it until it breaks".

Another challenge was ensuring that the right amount of information was given to the audience. The audience needed to be able to grasp the concepts and methods to enable them to contribute ideas and suggestions to any student's research work. However, too much information led to overload and a feeling of being overwhelmed with information, leading to a loss of interest in the presentation and work. A brief, simple introduction which outlines the current state of the art and the

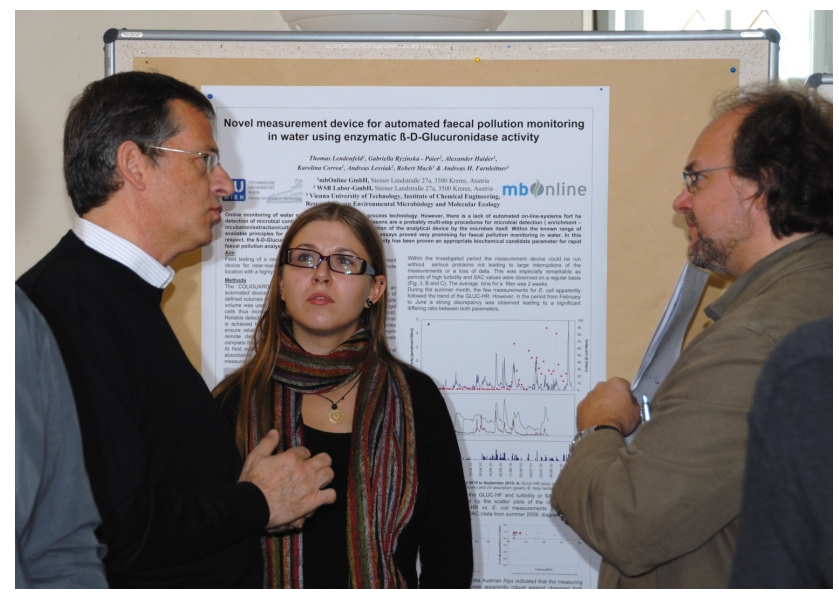

Fig. 5. Discussions during the annual symposium.

applications of the student's research was identified as being very important. A feedback session held after the symposium showed that discussion sessions were viewed very positively, but sufficient information on the research topics needed to be given in order that the audience were able to poise relevant questions and identify potential territory for collaborations and joint research questions.

In addition to providing a stimulating environment for identifying joint research questions, the symposium proved very effective at revealing differences in ways of thinking and perceptions to key concepts between the different disciplines. During one discussion, the different ways in which disciplines understand and deal with risk became very clear. Although the basic definitions are comparable, hydrologists and engineers deal with risk principally in terms of directly measurable numbers and statistics, whereas toxicologists or microbiologists often have to deal with complex biological models (for example, animal-testing) which does not allow for a direct and explicit calculation of human health risks. Besides the statistical based derivation of human health risks they often have to deal with risk minimisation concepts or comparable strategies (Blöschl et al., 2011b; Stalder et al., 2011).

Cluster meetings - many of the first level integration instruments also led to the development of joint research questions. The cluster group meetings were particularly effective because they brought together a small group of diverse researchers who were focussed around a specific research area. The soil moisture and scaling cluster combined hydrologists with remote sensing researchers. They focussed on combining their approaches to complement each other's research areas. A recent publication which emerged from this cluster group compares the effectiveness of soil moisture uncertainty estimates derived from satellite data to those derived from hydrological models (Doubkova et al., 2012). Interaction between microbiologists and hydrogeologists within the health related water quality cluster group led to the development 
and testing of a joint hypothesis that river level fluctuation reduces virus removal during river bank filtration. Numerical analysis showed that this is the case, and water level fluctuations do indeed reduce virus removal.

The courses also led to creative thinking and the development of joint research questions. By introducing students to governance and economics, a joint question between a social scientist and water quality and hydrology researchers has begun to explore how water management strategies, developed in collaboration with community participants, impact hydrological and environmental conditions. Within this research question, it is first paramount to devise suitable ways of measuring hydrological and environmental changes which fit to the temporal and spatial scales over which community collaboration activities have taken place. Researchers from many different fields are needed to contribute their skills, ideas and expertise to address this methodological challenge.

\subsubsection{Third level integration - joint study sites}

Joint study sites aim to further develop joint research questions, provide a setting for problem focussed creative thinking and a site for data collection and experimentation for research. The Doctoral Programme worked on several research sites, Petzenkirchen Hydrological Open Air Laboratory (HOAL), the Lobau wetlands, and some regional studies cover all of Austria.

Petzenkirchen HOAL - the 64 ha research catchment located about $100 \mathrm{~km}$ from Vienna is the major research site for several students whose theses explore: runoff processes; erosion and sediment transport; and quantifying nutrient inputs through agricultural drainage systems. Students spend a considerable amount of time at the site installing and operating the advanced instrumentation, sampling and running experiments. Sizable infrastructure funding from the Vienna University of Technology assisted in purchasing and installing state of the art equipment. During these activities students work in small groups to devise joint hypotheses, identify the optimal set-up for instrumentation, and design experiments that will help them all reach their aims (Fig. 6). For example, a flooding experiment was conducted in summer 2011 to assess how change in hydraulic conditions in the stream affects the sediment transport capacity and subsurface hydrology during a flood event. Ongoing work is also exploring the extent to which flow rate fluctuations are caused by processes in the riparian zone, the role of micro-pores in transferring precipitation to overland flow, the nature and role of flow paths for nutrient transport processes and the use of turbidity for estimating suspended sediment loads (see Eder et al., 2010).

Students working on this study site also have to pay close attention to social and economic factors and the "real world" problems of balancing multiple resource users in a concentrated area. Students are increasingly aware of the complexities of agricultural management practices. Fertiliser

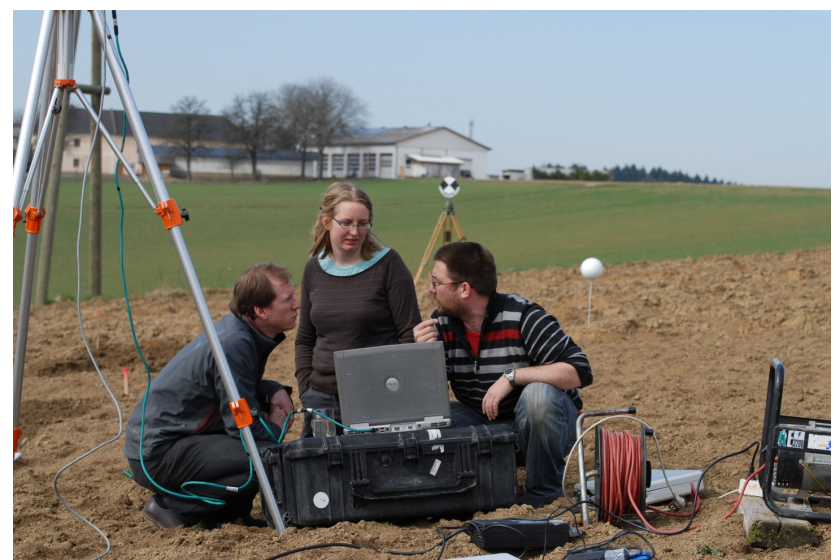

Fig. 6. Field work in the Petzenkirchen Hydrological Open Air Laboratory, a focus catchment located close to Vienna.

application and runoff to water ways is intricately connected to not only the seasonal, biological demands of the crop and the physical and chemical processes taking place at the land surface, but also to the socio-economics of agricultural production and the policies which regulate fertiliser applications.

The catchment provides students with first-hand experience of working with other disciplines on a joint research project and teaches them how interdisciplinary teamwork leads to more efficient and effective research. It also provides an education centre where students working in other areas and on other topics, such as, "Assessment of environmental changes for natural resources management in North Western Ethiopia", can develop research hypotheses and learn instrumentation and data collection methods. The site gives students who might not traditionally have conducted fieldwork the opportunity to spend time in the field learning about fieldwork methods. For example, the catchment provides a focus for a mainly computer-based structural engineer to collaborate with a mainly field-based soil scientist to explore runoff model identification. These experiences all demonstrate the value of the study sites for achieving interdisciplinarity.

Lobau wetlands - this multi-use wetland nature reserve on the edge of Vienna is a study site for several students researching diverse topics such as, "Terrain and land cover models from full-waveform Lidar measurements" and "Suspended load processes in streams and interactions with groundwater". A large resource of existing data from the site is complemented by further data collection through the Programme. Groundwater dynamics and the potential impact of land use and land use changes on groundwater quality is of particular interest. Joint research between a hydrogeologist and a remote sensing specialist is exploring how data on surface vegetation can be determined using airborne laser scanning data, and how this information can be used to improve the outputs of groundwater models applied to a flooding event (Vetter et al., 2011). Complementary work is 
exploring and modelling hydraulic interaction processes between rivers and groundwater (see Derx et al., 2010).

The area is politically complex as land management has to balance demands from tourism and recreation, nature protection and ground water abstraction for domestic purposes. Conflicts at the political level are intricate and students working in the area are exposed to these challenges and the impact they can have on their own research. Some ministerial departments can be sensitive over the publication of data and students (supported by supervisors) learn to negotiate political complexities.

Austria - students within the Programme are working at many different spatial scales. The country of Austria provides the focus for a hydrologist investigating regional flood frequency, a remote sensing researcher exploring large scale soil moisture and an environmental engineer investigating the impact of agricultural productivity and human consumption patterns on the country's water footprint (see Rogger et al., 2012 for the flood perspective).

\subsubsection{Summary of instruments for integration}

All the instruments used by the Doctoral Programme seem to contribute to integration. As expected, first level integration approaches help to achieve understanding between students, and enable them to communicate better with each other. $\mathrm{Su}-$ pervision and the annual symposium are important for initiating joint research questions across the entire Programme. However, joint study sites provide the most dynamic environment for really searching out and identifying research questions that are of interest to many different disciplines.

\subsection{Maintaining depth in an interdisciplinary programme (Challenge \#2)}

Cutting edge research is one of the key aims of the Doctoral Programme and to achieve this, students must become experts in their field of specialisation. To help students, the Programme has set up a number of requirements.

Thesis proposal - supervisors and students work closely together during the first months of the doctorate to develop the student's research proposal (a document of 15 to 20 pages that outlines the aim of the thesis, some background, the work-plan and a time schedule). Each research topic is different and some students request more supervisor involvement than others. Supervisors are available for their students, yet encourage them to take ownership of their research and develop their own ideas and strategies for tackling the topic. Students defend their proposal to the faculty, during which time the research approach is discussed and questions are raised by both the faculty and the other students. Supervisor support during the formation of the proposal helps to ensure that, to date, no student fails to produce a research proposal that is satisfactory. The process encourages students to think beyond their immediate work and put together a robust and realistic personal research agenda. We emphasise that putting together and defending a research proposal is intended to be constructive and enhance the quality of the students' own research.

Theses by journal publications - additionally, each student's thesis must be comprised of four, first author peer reviewed journal papers. Journals are selected in terms of thematic suitability and standing in the field (for example, ISI listed). Students are encouraged to submit work throughout their doctorate and it is therefore expected that several papers will be published within four years of study. To take account of the sometimes long turn-around time of journals, the PhD can be awarded if one or two papers are submitted, and the rest accepted or published. Some of the students who had completed their Master thesis on a topic different from their $\mathrm{PhD}$ thesis felt that four journal papers was a high target. However, two years into the Programme it seems that four journal papers can be achieved.

Thesis examination by international experts - the Programme is fully committed to the international standards for PhD education as discussed in EUA (2005) and follows guidance for European Doctorates (ROGET, 2007). This includes that an external, international expert forms one member of each student's thesis examination committee to ensure good practice (ROGET, 2007). We anticipate that almost all the students enrolled in the Programme will achieve their goal of earning a PhD. This is anticipated primarily because involvement in the Programme provides students with a high level of support from the faculty and their peer group. However, there is also a clearly defined exit route in case a student fails to meet the requirements.

International study exchange - each student also has the opportunity to spend six months abroad at an internationally renowned research institute for their area of specialisation. This gives students the opportunity to complement their training in Vienna with new methods and approaches and to develop their personal and research skills.

Regular feedback and evaluation - the Doctoral Programme must ensure that it functions in the most effective manner and provides students with the support they need to become part of the elite in their fields. A system of quality control has been adopted to continually monitor and improve the activities, decisions and actions made by the Programme. This includes annual reviews of the Programme by an external advisory panel comprised of three senior academic members from USA, Spain and Switzerland. Students have the opportunity to voice their concerns and offer their suggestions on the structure and running of the Programme during regular feedback sessions. Student representatives (elected by the students) sit on the Programmes steering committee and play an important role in liaising between the faculty and the student body. A recent change was to reduce the Programme's requirement for block course attendance. Students found that the requirement that they attended four block courses placed too much pressure on their time. The 
steering committee agreed and reduced the requirement to only one course over the four year period.

The instruments designed to achieve integration also help students achieve depth in their research. Mentoring through regular meetings with supervisors ensures that each student's progress and direction is continually assessed and necessary changes to their research agenda are identified and implemented. Cluster meetings have also been shown to be especially helpful in developing individual research. During the resource management cluster meetings, students present their work every six months to a cross-disciplinary audience of internal and sometimes external experts. The suggestions and ideas that emerge from these meetings enhance the depth of specific research being undertaken.

The ultimate assessment of whether the Programme achieves its aim of cutting-edge research will be the research outputs, primarily in the form of peer reviewed journal papers. To date, students involved in the Programme have collectively produced 10 published papers, with many more under review or in preparation. The collaborative work is of particular interest and although defining joint research questions and producing ground-breaking research in these areas has been identified as challenging, several papers are currently in preparation that are direct collaborations between students from different disciplines. The transfer of methods across fields is particularly promising, for example the application of model reduction techniques used in structural engineering to hydrological modelling. Many more papers have benefitted indirectly from cross-disciplinary discussions, ideas, data and methods.

\subsection{Teaching subjects remote from students' core expertise (Challenge \#3)}

Students have the opportunity to take a range of basic and advanced courses surrounding many different areas of water resource systems. The basic courses are compulsory and introduce students to the different ways of thinking, approaches and terminology used by different academic disciplines. The course programme was designed to develop individuals who could successfully interact with and benefit from people in other disciplines, rather than create individuals who were experts in all fields. To convey approaches and ideas, lecturers have to find ways to communicate concepts and world views (such as those held by ecologists and physicists in Table 1). Lecturers were all aware that teaching to a heterogeneous group (in terms of knowledge, experience and interests) would present challenges and embraced the opportunity to explore new approaches and methods to communicate their subjects.

The disciplinary backgrounds of the students in the Programme is diverse and covers mathematics, civil engineering (structural, resource management, hydrology and water quality), soil science, chemistry, environmental engineering, geology, geography and biology. Lecturers realised that to successfully communicate they needed to be aware of the background of each student, and relate this background to the students' perception of the world and their expected understanding of the concepts being taught. Several approaches were applied:

Visually explicit teaching - complex themes are taught through images rather than equations and text. For example, in the course on modelling and simulation methods the topic of Fourier transforms was explained by visuals that highlighted the similarities with the spectrum of light rather than a formal derivation based on equations. Similarly, differential equations for first order decay of concentrations in a lake was visualised graphically instead of with formal derivations. Basic concepts to derive water safety plans for protection of drinking water resources were developed and discussed in group work during the examination of the course "Health related water quality targets and urban water management".

Cross relating to associated subjects - the similarity between heterogeneities in soils and masonry were highlighted to environmental science and engineering students. Similarly, methods to describe problems in terms of differential equations and strategies to solve them are almost identical in hydrogeology and structural dynamics. The essential role of hydrology for any water quality related question was highlighted to chemists, biologists and microbiologists. Case studies were used to illustrate risk, hydrology, water quality and water resources management. Also, differences in nomenclature among the scientific disciplines were explicitly addressed in the basic study courses. For example, in hydrology the term "process" relates to the physical mechanism of rainfall while in statistics "process" relates to the characteristics of a time dependent random variable such as rainfall rate.

Learning by doing - a lecture on water governance and decision-making processes was followed by a structured role playing game to illustrate management challenges. Each student was allocated the role of a group representative in a fictitious city in the process of upgrading their water management plan (for example, city mayor, head of the water commission, representative from the agricultural, etc.). Each role was given specific instructions on conditions they would and would not agree to within the management plan. They were then told to reach a decision through discussion and negotiation. Students reported that they found the exercise very useful for visualising decision making processes, governance structures and power systems, and understanding the complexities of real world decisions due to multiple interests and agendas.

Extra-mentoring - lecturers often provided extra sessions to cover challenging topics such as calculus. These sessions taught the topic at the speed of the slowest person in the group. Revision groups were held to recap and address weak areas before examinations. Both of these approaches were essential for bringing all students up to an equal level 
on all basic study courses by the end of the first year of the Programme.

Bringing in external experts - external experts with experience of teaching their topic to multi-disciplinary postgraduate students taught some of the block courses. For example, an economist from a centre for environmental research taught a valuable course on the economics of water. This was complemented by a policy scientist who taught a course on water governance. These courses were taught in general terms and introduced basic principles to serve as a foundation for future work in these areas.

The Programme also offered a number of short courses on soft skills. For example, a course on writing a scientific paper was appreciated by the students and a similar course was held for a wider audience during the 2011 General Assembly of the European Geosciences Union (Blöschl, 2011). Some of the students also attend language courses to complement their existing language skills.

\subsection{The human factor}

The approaches for integration, ensuring depth in personal research and teaching specialised topics to a diverse disciplinary group are all influenced by personal characteristics and dynamics between individuals. Successful integration relies on trust and connectivity between individuals (Renzl, 2008). Trust is essential to allow free and open dialogue that allows creativity to emerge. Trust means that individuals can focus their energies on working together rather than monitoring each other to ensure they act as expected (Pretty and Ward, 2001). Connectivity ensures that channels for information exchange exist which enables individuals to work together. Interdisciplinary programmes are known for their difficulties in developing trust and connectivity because of the different world views held by different disciplines, difficulties in communication and differing ideas on research priorities (Mills et al., 2011).

Faculty - the Doctoral Programme was built upon longstanding experiences of collaboration between faculty members. Numerous joint proposals had been funded and projects had been completed between members of the Programme on topics such as snow modelling and remote sensing, soil moisture estimation, nutrient balancing in the Danube countries and treated wastewater infiltration as a method for disposal in remote locations. These collaborative projects had led to dozens of joint publications prior to the Programme. Faculty members had also taught undergraduate and masters level courses jointly on topics relating to modelling and designing water management systems. These experiences had built personal relationships and mutual trust between the faculty members. These initial starting conditions are likely to be very important when setting up and implementing an interdisciplinary doctoral programme.

Students - at the start of the Programme new students were brought together in a new setting and trust and connectivity needed to be developed. The first, second and third level approaches for integration (described in Sect. 3.2) focus on building trust and developing connectivity between students. Our experiences suggest that some specific attention is needed to foster trust and build relationships to the extent where free and open discussion can take place between individuals for developing joint research questions. Early in the Programme a dispute arose between two students over the intellectual property rights of a set of research questions. The questions had been put together through individual and collaborative work on a similar topic. This had led the students to reach similar ideas on their research direction. A joint meeting was able to show the students that the process of idea formation had revealed many similar research ideas and helped them to identify the overlap and differences between their planned work. This ultimately strengthened their collaboration over the following years. This experience suggests that joint meetings should be held regularly and it should be explained to students that overlapping research will emerge and is a good product from integration.

In addition to the many informal social gatherings, particularly at the start of the Programme, the annual symposium was especially important for developing personal and professional relationships between Programme members (Fig. 7). This was held at a retreat away from the university and included an overnight stay. The schedule for the symposium included an afternoon session for team-building activities which created a relaxed atmosphere and is likely to have helped form relationships, connections and trust. Our experiences suggest that these aspects are important and should be included within any interdisciplinary doctoral programme. It may also be beneficial to run a symposium early to "jumpstart" the process of forming connections and trust between all individuals.

\section{Programme benefits and lessons learned}

Experiences from the first year of the Programme indicate that the objectives (interdisciplinary, international and cutting-edge research) are being achieved. Interdisciplinary integration is emerging and can be seen by the numerous joint research questions described throughout this paper that are being developed and put into action through collaborative research plans. The Programme is clearly international because the 23 students involved in the Programme come from more than 10 countries. Courses, seminars and conferences organised and attended by Programme participants bring students into contact with some of the world's best experts. We imagine that that the research semester abroad will further develop each student's connection to their international research community. More than 10 publications in peer reviewed journals have been produced at this early stage of the Programme with many more under review or 


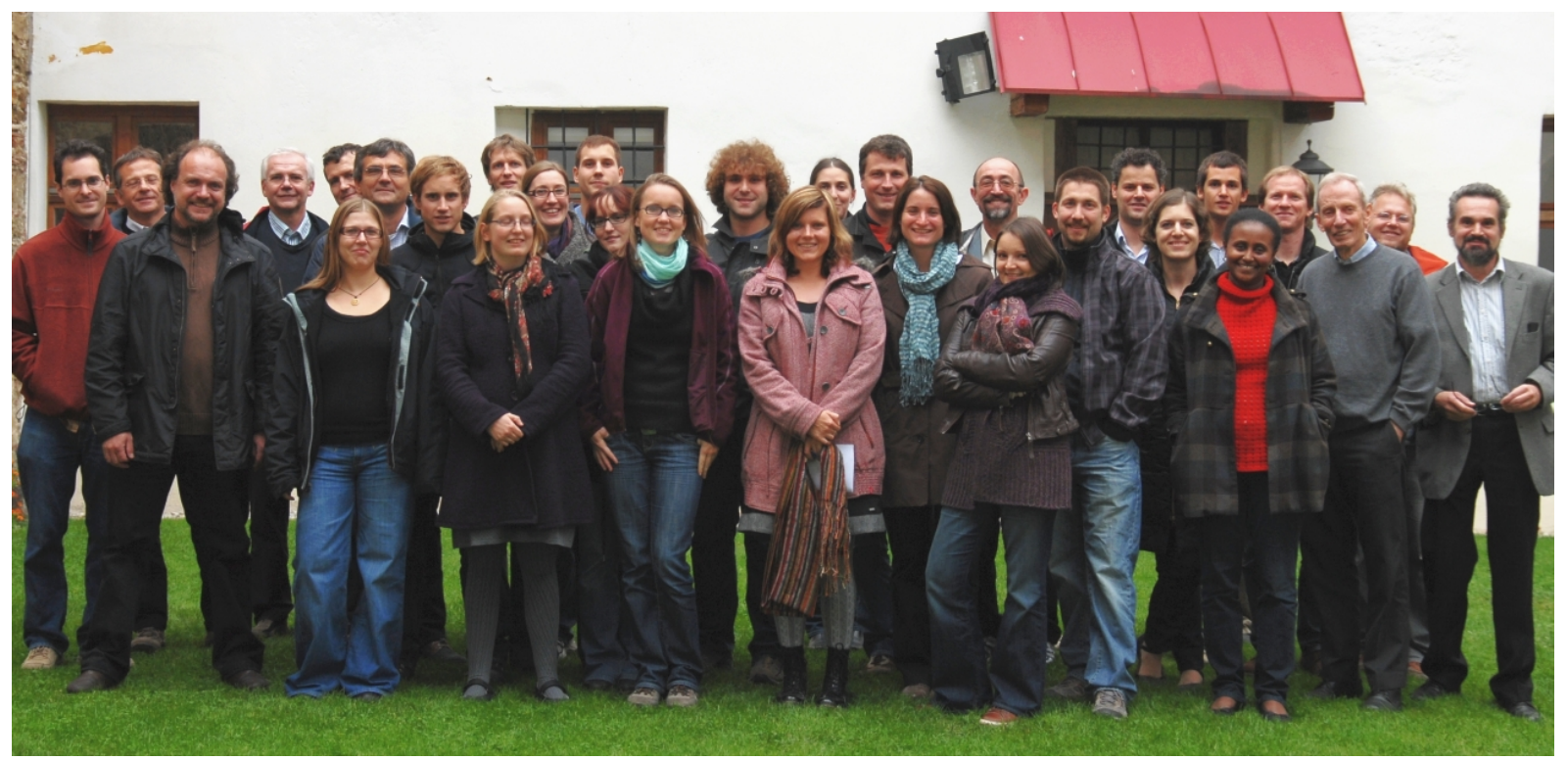

Fig. 7. Students and faculty of the Vienna Doctoral Programme on Water Resource Systems.

in preparation. This suggests that students are conducting cutting-edge research.

\subsection{Benefits}

From our experiences, we believe that an interdisciplinary programme has the potential to provide a number of benefits to students, its host university and to academia and the scientific community.

\subsubsection{Benefits to students}

The students of the Programme are expected to work collaboratively with others from different research fields. We have seen how students working at Petzenkirchen HOAL share monitoring resources and data, and work cooperatively to use each other's strengths to develop joint solutions to problems. Recently, a number of students worked together to design and install a unique water quality monitoring system. This demonstrates aptitude to teamwork which is a distinctive skill for doctoral graduates. This suggests to us that graduates of the Programme, who have both specific expertise and team work skills, may perhaps have a career advantage over graduates from single discipline doctoral programmes.

From our observations, students of the Programme are developing considerable depth in their area of specialisation. However, they are also developing an ability to relate their research to other specialisations. During discussions, students regularly ask each other how they might integrate their research topics and discuss creative applications for either their own work or the work of their peers. This integrated thinking that seems to be emerging suggests to us that graduates will be in a strong position to understand the complexities of water resource system management, and develop innovative solutions to the problems, in collaboration with others.

The students of the programme are confident and outgoing and seem to be embracing the opportunities for developing their own network from conferences, seminars and international research exchange. It is hoped that by the time graduates complete their $\mathrm{PhD}$ they will be well connected to the international research community which will be beneficial to them in their future careers. It is also hoped that many of the relationships and networks forged between students during the Programme will remain after their graduation, leading to benefits associated with an interdisciplinary network.

\subsubsection{Benefits for Vienna University of Technology}

We received 600 applications for nine positions in 2009 and we hope that we will continue to receive applications from high calibre candidates. From what we can see, this influx of talent has created a highly dynamic and capable research centre within the university. The Centre is gaining international visibility. For example, the Centre was invited to take part in a tender for an EU Project to investigate the impact of climate change on drinking water in Europe specifically because the initiators of the tender recognised the strengths that the Programme's broad skills and languages (more than 13 languages are covered by members of the Programme) would strengthen their application.

Over the longer term, we believe that the Programme is creating a strong multi-national group of alumni who we anticipate will become future leaders of the water sector. Their current and future achievements will reflect positively on Vienna University of Technology. Similarly, the Programme is leading to the development of much new collaboration 
with leading institutions at the global level. We look forward to developing these collaborations further over the coming years to continuing to strengthen the quality of research taking place at Vienna University of Technology.

\subsubsection{Benefits to academia and the scientific community}

The Programme can be thought of as an experiment in interdisciplinary research and education. It has been developed through examining the successes of other programmes and provides further evidence to the education and research community that interdisciplinary doctoral programmes can work but they require careful implementation and support. The set up and experiences from the Programme has been presented at international conferences (Blöschl et al., 2010, 2011a). Other institutes have shown considerable interest in how the Programme has been arranged and how it is functioning. This interest may be in part due to the increasing emphasis from funders, students and employers for interdisciplinary education and research. Institutes are also recognising the potential benefits to science from integrating disciplines and identifying new science questions where disciplines interplay.

\subsection{Challenges}

Our experiences of setting up and implementing the Vienna Doctoral Programme on Water Resource Systems have revealed many benefits. We have also encountered expected and unexpected challenges:

- The Programme is intensive and time demanding. Students become experts in their own field of specialisation and develop understanding of many other fields to the extent that they can work with concepts, ideas and approaches within their own research. We use courses, journal clubs, cluster meetings and symposia to develop these skills. These approaches do give students a good understanding of other research disciplines, but require time, energy and motivation. This reduces the time available for students to work on their individual research. Our experience shows that group courses should be concentrated into the first year of the $\mathrm{PhD}$ when research ideas are being developed. This means that during subsequent years the majority of time is designated to individual research.

- An interdisciplinary $\mathrm{PhD}$ requires four years rather than three years (traditionally expected for a disciplinary thesis). The additional time needed to complete a $\mathrm{PhD}$ in an interdisciplinary programme must be factored in by funders, students and supervisors.

- Developing joint research questions is difficult. The Programme recognised that students would find it challenging to identify areas of overlapping interest however, we have also found that joint research questions have emerged between students from very different research fields. The cluster meetings, annual symposia and supervision have all contributed to these achievements. Regular meetings between students and their joint supervisors are beneficial.

- One of the critical challenges is to balance the importance of free and creative thinking that may sometimes lead to research findings that are difficult to publish, against the importance of publications. Our efforts to address this are shaped by the mechanisms and support systems described in the paper. These are designed to create a "free" environment where creativity blossoms, but which support students and focus their energies onto research topics where results are achievable.

\subsection{Lessons learnt}

We have identified some important lessons that may be useful to others planning or implementing an interdisciplinary doctoral programme:

- Select candidates who show capacity to integrate with others and willingness to work as part of a team.

- Cultivate team work and explain that joint research questions and collaborations emerge out of joint work.

- Hold symposia as often as possible and ensure that they take place away from the normal place of work. It may also be beneficial to hold a symposium early on in the programme to give students the opportunity to learn about one another and their planned research.

- Build on existing relationships between faculty members. Our experience suggests that a successful programme will build on relationships and mutual trust that exists between faculty members prior to the programme. Interdisciplinary doctoral programmes should exploit strong existing relationships demonstrated by a history of collaborations.

- Use a problem-orientated approach. Our experiences show that students are interested in exchanging research ideas and methods centred on a specific problem. Cluster group meetings that worked well took a problem focussed approach and, for example, searched out creative applications for existing methods. The research study sites were especially good for providing a clear and applied focus for joint problem solving and are highly recommended for any interdisciplinary doctoral programme.

- Adapt teaching to meet the interests and needs of an interdisciplinary group. Courses that were viewed positively were those that had a good introduction and were highly interactive with plenty of opportunity to ask questions. 
- Pay special attention to communication. During symposia and meetings we continually emphasized that it is the responsibility of the presenter to ensure that all members of the programme are able understand the work being described. Simple terminology, graphics and describing work in applied terms all help to achieve this. We have learnt that allocating more time for large and small group discussion is better than allocating more time to individual presentations.

- Hold regular feedback and assessment sessions. The Programme benefited from regular feedback sessions and continual assessment, modification and improvement to its structure based on the experiences of students and supervisors. Active feedback was sought following every semester of courses and block courses and after each symposium. Regular faculty meetings and student representation on the Steering Committee meant that issues and ideas were brought into a setting where decisions on Programme adjustments could be made.

\section{Conclusions}

The Vienna Doctoral Programme provides an example of how an interdisciplinary doctoral programme can be arranged and implemented. Our experiences show that challenges are to be expected and they can broadly be grouped around the areas of integration, ensuring graduates have depth to their expertise, and teaching specialist subjects to non-specialists.

In this paper we have presented our experiences of these challenges and described how we have attempted to overcome them. Our strategy has been based on a mixture of structured and unstructured arrangements:

- Structured education programme.

- Create opportunities for informal communication.

- Structured and informal mentoring.

- Flexibility in programme structure based on feedback.

The Doctoral Programme is a joint learning exercise between students, supervisors and all research and education partners involved. The Programme provides an intense education experience to its students, provides added value to the university, and is starting to lead to significant contributions to science. Our experiences show that it is possible to integrate students from many disciplines while still maintaining a high quality research programme. It is also possible to teach specialist subjects to non-specialists. We also believe that in order to open up boundaries between disciplines students need to understand that different disciplines not only speak different languages but think differently as well. The Programme's initial experiences suggest that students can make significant progress in understanding how other disciplines think, and that this development is an important achievement from an interdisciplinary education.

Time availability and management of time are critical factors. While a doctorate completed in a traditional programme may take three years our experience suggests that a doctorate within an interdisciplinary programme will require four years. This is because of the additional course work demands and integration activities which expand away from the student's area of specialisation. Activities need to be prioritised and careful judgement is needed to assist the student in decisions relating to the allocation of their time. Our experiences have shown that implementing and running an interdisciplinary doctoral programme has its challenges and is demanding in terms of time and human resources but seeing interactions progress and watching people grow and develop their way of thinking in an interdisciplinary environment is a valuable reward.

Acknowledgements. The authors would like to acknowledge financial support provided by the Austrian Science Fund (FWF) as part of the Vienna Doctoral Programme on Water Resource Systems (DK-plus W1219-N22). Matching funds have been provided by the Vienna University of Technology for which the authors are grateful. They would also like to pass on their sincere gratitude to the rectorate of the Vienna University of Technology and particularly Sabine Seidler and Adalbert Prechtl. Their dedicated work and commitment to interdisciplinary research and training have been instrumental for establishing and running the Doctoral Programme. The authors would also like to thank Peter Strauß and Regina Sommer for their collaboration in the focus catchments, and Anicet Blanch, Pete Loucks and Eberhard Morgenroth for their service on the advisory board.

Edited by: T. Wagener

\section{References}

Blöschl, G.: Hydrologic synthesis: Across processes, places, and scales, Water Resour. Res., 42, W03s02 doi:10.1029/2005wr004319, 2006.

Blöschl, G.: How to write (and publish) a scientific paper in hydrology, available at: http://www.egu.eu/fileadmin/user_upload/ Division_HS/how_to_write_bloe.pdf, last access: 8 November 2011, 2011.

Blöschl, G., Bucher, C., Carr, G., Farnleitner, A. H., Rechberger, H., Wagner, W., and Zessner, M.: Promoting Interdisciplinary Education: The Vienna Doctoral Programme on Water Resource Systems, Geophysical Research Abstracts, 12, EGU2010-1802, EGU General Assembly 2010, Vienna, Austria, 2010.

Blöschl, G., Bucher, C., Carr, G., Farnleitner, A. H., Rechberger, H., Wagner, W., and Zessner, M.: The Vienna Doctoral Programme on Water Resource Systems: Achievements and challenges of an interdisciplinary research and education programme, Geophysical Research Abstracts, 13, EGU2011-3430, EGU General Assembly 2011, Vienna, Austria, 2011a. 
Blöschl, G., Takeuchi, K., Jain, S., Farnleitner, A., and Schumann, A.: Preface, in: Risk in water resources management, IAHSAISH P., 347, IAHS Press, Wallingford, 2011b.

Castán Broto, V., Gislason, M., and Ehlers, M. H.: Practising interdisciplinarity in the interplay between disciplines: experiences of established researchers, Environmental Science and Policy, 12, 922-933, 2009.

Derx, J., Blaschke, A. P., and Blöschl, G.: Three-dimensional flow patterns at the river-aquifer interface - a case study at the Danube, Adv. Water Resour., 33, 1375-1387, 2010.

Doubkova, M., van Dijk, A., Sabel, D., Wagner, W., and Blöschl, G.: Evaluation of the predicted error of the soil moisture retrieval from C-Band SAR by comparison against modelled soil moisture estimates over Australia, Remote Sens. Environ., in press, 2012.

Eder, A., Strauss, P., Krueger, T., and Quinton, J. N.: Comparative calculation of suspended sediment loads with respect to hysteresis effects (in the Petzenkirchen catchment, Austria), J. Hydrol., 389, 168-176, 2010.

EUA: Doctoral Programmes for the European Knowledge Society, Report on the EUA Doctoral Programmes Project 2004-2005, European University Association, Brussels, 2005.

Gold, C. M. and Gallagher, H. A.: The challenges of conducting interdisciplinary research in traditional doctoral programs, Ecosystems, 2, 281-285, 1999.

Harte, J.: Toward a synthesis of the Newtonian and Darwinian worldviews, Phys. Today, 5, 29-34, 2002.

Hufschmidt, M.: The Role of Universities in Water Resources Education: The Social Sciences, Water Resour. Res., 3, 3-9, 1967.

Mills, J. E., Gill, J., Sharp, R., and Franzway, S.: Getting it together: Feminist interdisciplinary research on women and engineering, Women Stud. Int. Forum, 34, 13-19, 2011.

Nelson, B.: Seeking the right toolkit, Nature, 476, 115-117, 2011.

Petrie, H. G.: Do you see what I see? The epistemology of interdisciplinary inquiry, J. Aesthet. Educ., 10, 29-43, 1976.

Pretty, J. and Ward, H.: Social capital and the Environment, World Dev., 29, 209-227, 2001.
Price, R.: My picture is bigger than your picture: as if size matters. Proceedings of the 9th National PURSL Conference, Rockhampton Queensland 29 September to 2 October 2003, 2003.

Redclift, M.: Dances with wolves? Interdisciplinary research on the global environment, Global Environ. Chang., 8, 177-182, 1998.

Renzl, B.: Trust in management and knowledge sharing: The mediating effects of fear and knowledge documentation, Omega, 36, 206-220, 2008.

ROGET: Guidance for European Doctorates, Research Office Graduate Education Team, Manchester University, 2007.

Rogger, M., Pirkl, H., Viglione, A., Komma, J., Kohl, B., Kirnbauer, R., Merz, R., and Blöschl, G.: Step changes in the flood frequency curve - process controls, Water Resour. Res., in review, 2012.

Stalder, G., Sommer, R., Walzer, C., Mach, R. L. Beiglböck, C., Blaschke, A. P., and Farnleitner, A. H.: Hazard- and risk based concepts in microbiological water quality determination - part 1, Veterinary Medicine Austria, 98, 9-24, 2011.

Thompson, S. E., Harman, C. J., Schumer, R., Wilson, J. S., Basu, N. B., Brooks, P. D., Donner, S. D., Hassan, M. A., Packman, A. I., Rao, P. S. C., Troch, P. A., and Sivapalan, M.: Patterns, puzzles and people: implementing hydrologic synthesis. Hydrol. Process., 25, 3256-3266, 2011.

Vetter, M., Höfle, B., Hollaus, M., Gschöpf, C., Mandlburger, G., Pfeifer, N., and Wagner, W.: Vertical vegetation structure analysis and hydraulic roughness determination using dense ALS point cloud data - a voxel based approach. ISPRS Workshop Laser Scanning 2011, 29-31 August, University of Calgary Calgary, Alberta, Canada, 2011.

Wagner, C. S., Roessner, J. D., Bobb, K., Klein, J. T., Boyack, K. W., Keyton, J., Rafols, I., and Börner, K.: Approaches to understanding and measuring interdisciplinary scientific research (IDR): A review of the literature, J. Informetr., 165, 14-26, 2011.

Wolman, M. G.: Interdisciplinary education: a continuing experiment, Science, 198, 800-804, 1977. 